\title{
Hydrogen gettering in annealed oxygen-implanted silicon
}

\author{
A. Misiuk ${ }^{1}$, A. Barcz ${ }^{1}$, A. Ulyashin ${ }^{2}$, I.V. Antonova ${ }^{3}$, M. Prujszczyk ${ }^{1}$ \\ ${ }^{I}$ Institute of Electron Technology, Al. Lotnikow 46, 02-668 Warsaw, Poland \\ Phone: +48 22 5487792; fax: + 4822 8470631; \\ E-mails: misiuk@ite.waw.pl; barcz@ite.waw.pl; prujsz@ite.waw.pl \\ ${ }^{2}$ SINTEF, P.O. Box 124 Blindern, NO-0314 Oslo, Norway \\ Phone: +47 95480849; fax: +47 22067926; e-mail: alexander.g.ulyashin@sintef.no \\ ${ }^{3}$ Institute of Semiconductor Physics, SB RAS, pr. Lavrentieva, 13, Novosibirsk, Russia; \\ Phone: (7 3832) 332493; fax: (7 3832) 332771; e-mail: antonova@isp.nsc.ru
}

\begin{abstract}
Hydrogen gettering by buried layers formed in oxygen-implanted silicon ( $\mathrm{Si}: \mathrm{O}$ prepared by $\mathrm{O}_{2}^{+}$implantation at the energy $200 \mathrm{keV}$ and doses $10^{14}$ and $10^{17} \mathrm{~cm}^{-2}$ ) was investigated after annealing of $\mathrm{Si}: \mathrm{O}$ at temperatures up to $1570 \mathrm{~K}$, including also processing under enhanced hydrostatic pressure, up to $1.2 \mathrm{GPa}$. Depending on processing conditions, buried layers containing $\mathrm{SiO}_{2-\mathrm{x}}$ clusters and/or precipitates were formed. To produce hydrogen-rich $\mathrm{Si}: \mathrm{O}, \mathrm{H}$ structures, $\mathrm{Si}$ :O samples were subsequently treated in $\mathrm{RF}$ hydrogen plasma. As determined using secondary ion mass spectrometry, hydrogen was accumulated in sub-surface region as well as within implantation-disturbed areas. It has been found that hydrogen was still present in $\mathrm{Si}: \mathrm{O}, \mathrm{H}$ structures formed by oxygen implantation with the dose $D=10^{7} \mathrm{~cm}^{-2}$ even after post-implantation annealing up to $873 \mathrm{~K}$. It is concluded that hydrogen accumulation within the disturbed areas in $\mathrm{Si}: \mathrm{O}$ as well as in SOI structures can be used for recognition of defects.
\end{abstract}

Keywords: $\mathrm{Cz}-\mathrm{Si}$, implantation, oxygen, hydrogen, high temperature, high pressure, gettering, defects.

Manuscript received 02.02.10; accepted for publication 25.03.10; published online 30.04.10.

\section{Introduction}

Silicon-on-insulator structures (SOI) can be produced by $\mathrm{O}_{2}{ }^{+}$implantation into Czochralski grown silicon $(\mathrm{Cz}-\mathrm{Si})$ at doses $D \geq 2 \cdot 10^{17} \mathrm{~cm}^{-2}$ and subsequent annealing of resulting $\mathrm{Si}: \mathrm{O}$ at high temperatures (HT) approximately up to $1600 \mathrm{~K}$ [1]. Microstructure of the SOI samples depends, among other factors, on the implanted oxygen ion energy $E$, on $D$, HT and on processing time $t$. An enhanced hydrostatic pressure (HP) applied upon processing of the $\mathrm{Si}: \mathrm{O}$ samples results in formation of specific structures with an improved quality of the $\mathrm{SiO}_{\mathrm{x}} / \mathrm{Si}$ interface $[1,2]$.

In the case of self-implanted silicon ( $\mathrm{Si}: \mathrm{Si}$ ), buried defect layers can getter hydrogen embedded into Si from hydrogen plasma [3]. This effect is now investigated for the SOI-like structures produced from $\mathrm{Si}: \mathrm{O}$ prepared by oxygen implantation into $\mathrm{Cz}-\mathrm{Si}$ with the doses of $D \leq 1 \cdot 10^{17} \mathrm{~cm}^{-2}$ and processed under HT-HP $[1,2,4]$. Such structures are interesting in view of possible application of the hydrogen decoration/gettering for the recognition of the structural defects in SOI-like structures.

\section{Experimental}

$\mathrm{Cz}-\mathrm{Si}$ wafers of $(001)$ orientation and the interstitial oxygen concentration $c_{\mathrm{O}} \approx 1 \cdot 10^{18} \mathrm{~cm}^{-3}$ were implanted with $\mathrm{O}_{2}^{+}$at room temperature. Sample labelling and implantation parameters are listed in Table.

Afterwards, the $\mathrm{Si}$ :O samples were annealed for up to $10 \mathrm{~h}$ in purified Ar atmosphere at $\mathrm{HT} \leq 1570 \mathrm{~K}$ under $\mathrm{HP} \leq 1.2 \mathrm{GPa}$.

To introduce hydrogen, the $\mathrm{Si}: \mathrm{O}$ samples were subsequently treated for $2 \mathrm{~h}$ at $530 \mathrm{~K}$ in $\mathrm{RF}$ hydrogen plasma by using a plasma enhanced chemical vapour deposition (PECVD) reactor [3].

Table. Sample labelling, $E, D$ (calculated for implanted oxygen atoms) and projected range of implanted ions, $R_{p}$.

\begin{tabular}{|c|c|c|c|}
\hline Sample & $E, \mathrm{keV}$ & $D, \mathrm{~cm}^{-2}$ & $R_{p}, \mathrm{~nm}$ \\
\hline $\mathrm{A}$ & 200 & $1 \cdot 10^{14}$ & 400 \\
\hline $\mathrm{B}$ & 200 & $1 \cdot 10^{17}$ & 400 \\
\hline
\end{tabular}


The depth profiles of hydrogen and oxygen in the as-prepared $\mathrm{Si}: \mathrm{O}, \mathrm{H}$ samples as well as in the samples subjected to subsequent annealing for $1 \mathrm{~h}$ at $723 \mathrm{~K}$ or $873 \mathrm{~K}$ were determined using secondary ion mass spectrometry (SIMS) with $\mathrm{Cs}^{+}$ions for sample sputtering. Transmission electron microscopy (TEM) was used for defect structure determination.

\section{Results and discussion}

Two types of Si:O samples were investigated (Table): samples A were prepared by low dose $\mathrm{O}_{2}^{+}$implantation. In what follows, they will be considered as the reference ones. The B samples were prepared by implantation with the oxygen dose only 2-3 times lower than that used in high dose SIMOX processing $\left(D \geq 2 \cdot 10^{17} \mathrm{~cm}^{-2}\right)$. In both cases implantation resulted in the creation of an amorphous silicon ( $\mathrm{a}-\mathrm{Si}$ ) layer in the projected range $\left(R_{p}\right)$ area.

Upon annealing, this $\mathrm{a}-\mathrm{Si}$ buried layer was subjected to solid phase epitaxial re-growth (SPER). Depending on the HT, HP and other processing conditions, buried $\mathrm{SiO}_{2-\mathrm{x}}$ nanoclusters, precipitates and/or semi-continuous layers can be formed near $R_{p}$ [6].

The treatment of the as-implanted reference sample $\mathrm{A}$ in hydrogen plasma resulted in a remarkable hydrogen enrichment of the sub-surface area, up to about 300-nm depth, while no hydrogen was observed near $R_{p}$ (Fig. 1).

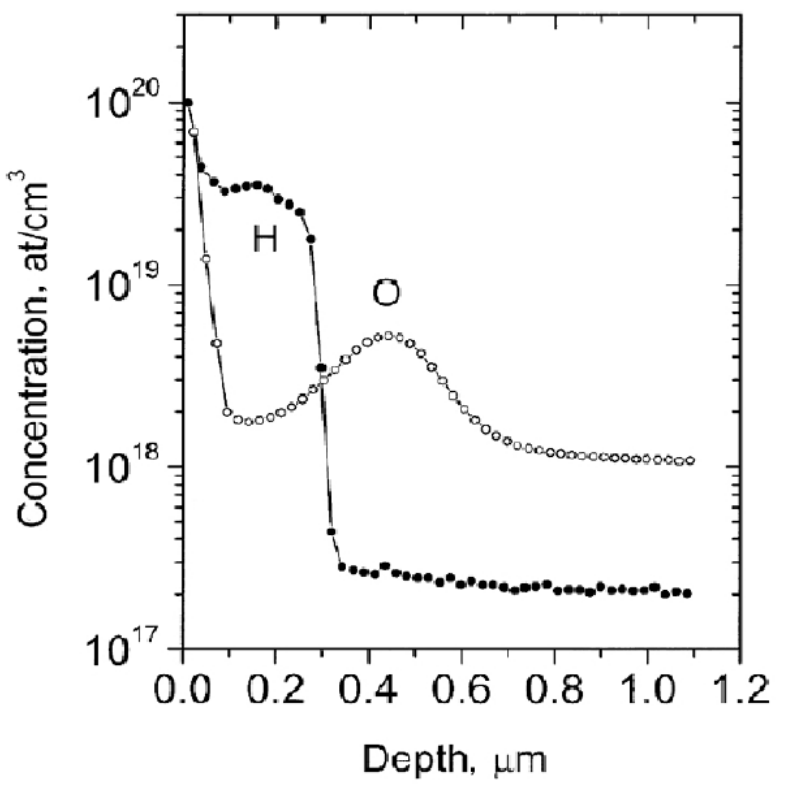

Fig. 1. SIMS depth profiles of oxygen and hydrogen in $\mathrm{Si}: \mathrm{O}, \mathrm{H}$ structure obtained for the as-implanted A Si:O sample.

Surface enrichment with hydrogen can be attributed to the in-diffusion of hydrogen towards the sub-surface defect area disturbed by hydrogen plasma treatment itself as well as to the presence of near-surface defects induced due to oxygen implantation.
No hydrogen gettering near $R_{p}$ was detected in the reference samples A after the plasma treatment and processing at $923 \mathrm{~K}$ (Fig. 2) as well as at higher temperatures. The near-surface hydrogen-enriched layer was, however, much narrower (compare Figs 2 and 1). This means that most of implantation-induced defects formed by implantation of $\mathrm{O}_{2}^{+}$ions are healed at $T \geq 923 \mathrm{~K}$ upon HT(HP) processing of low dose implanted samples. As a result, in-diffusion of hydrogen during the plasma treatment was limited to the depths below $100 \mathrm{~nm}$ (Fig. 2). The relatively small damages near $R_{p}$ in the A Si:O samples were healed in effect of SPER, so they did not create the gettering sites for accumulation of hydrogen.

For the as-implanted B Si:O sample ( $D=1 \cdot 10^{17} \mathrm{~cm}^{-2}$ ), plasma treatment leads to the almost depth-independent accumulation of hydrogen within the sub-surface area up to about 200-nm depth, with $c_{\mathrm{H}}=1 \cdot 10^{20} \mathrm{~cm}^{-3}$. This treatment of the as-implanted B $\mathrm{Si}$ :O sample (prepared using the $10^{3}$ higher dose of implanted oxygen comparing to that in the $\mathrm{A} \mathrm{Si}: \mathrm{O}$ sample, Table) also does not result in remarkable hydrogen content near $R_{p}$.

Contrary to the case of as-implanted $\mathrm{Si}: \mathrm{O}, \mathrm{H}$ sample $\mathrm{B}$, the hydrogen content within the deeper areas of the $\mathrm{B}$ $\mathrm{Si}$ O,H samples processed at $920-1570 \mathrm{~K}$ follows in general the profile of implanted oxygen and depends on HP applied upon processing (Figs 3, 4, 6, 7).

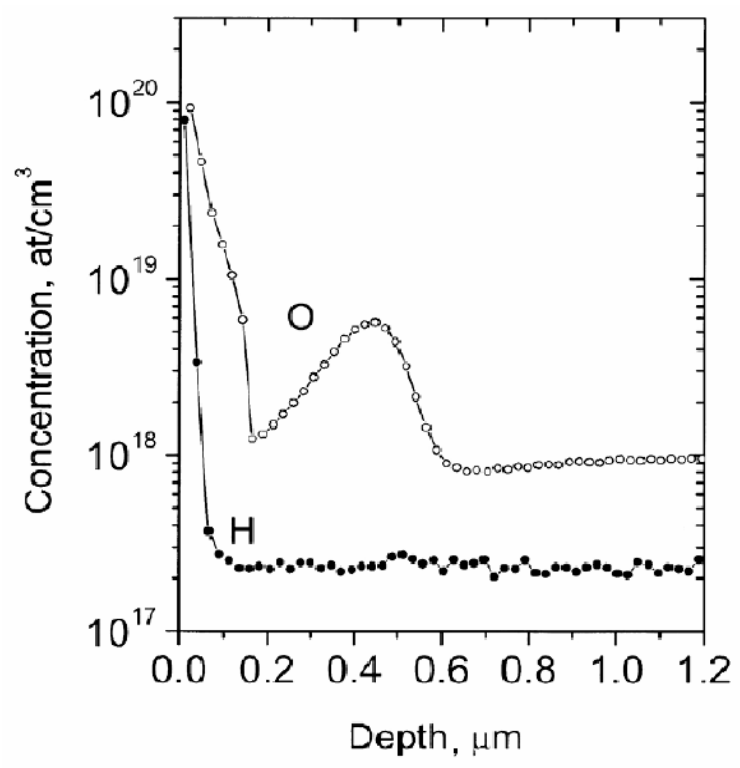

Fig. 2. SIMS depth profiles of oxygen and hydrogen in $\mathrm{Si}: \mathrm{O}, \mathrm{H}$ structure obtained for the A Si:O sample processed for $10 \mathrm{~h}$ at $923 \mathrm{~K}$ under $10^{5} \mathrm{~Pa}$.

Processing the B Si:O sample at $923 \mathrm{~K}$ results in a distinguished hydrogen gettering near $R_{p}$, with the hydrogen concentration $c_{\mathrm{H}}$ reaching $7 \cdot 10^{18} \mathrm{~cm}^{-3}$ (Fig. 3, compare to Fig. 2). 


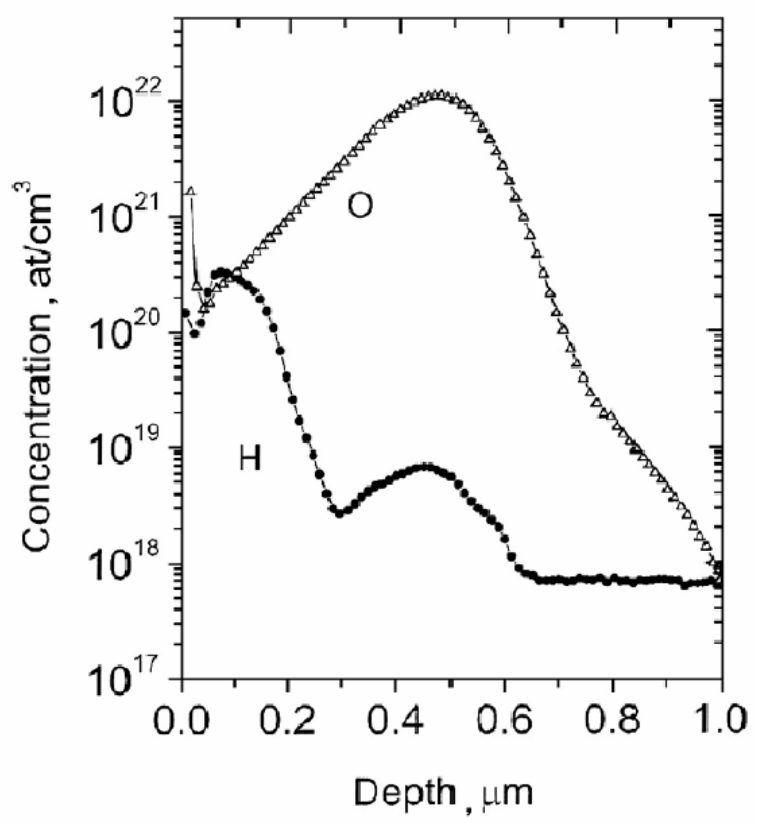

Fig. 3. SIMS depth profiles of oxygen and hydrogen in $\mathrm{Si}: \mathrm{O}, \mathrm{H}$ structure obtained for the B Si:O sample processed for $10 \mathrm{~h}$ at $923 \mathrm{~K}$ under $10^{5} \mathrm{~Pa}$.

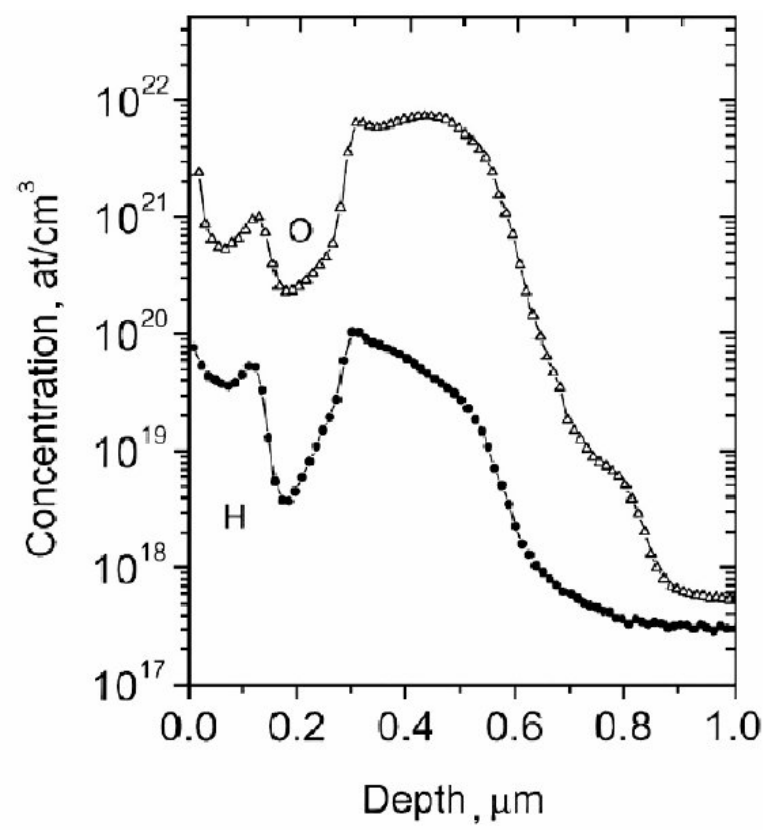

Fig. 4. SIMS depth profiles of oxygen and hydrogen in $\mathrm{Si}: \mathrm{O}, \mathrm{H}$ structure obtained for the B Si:O sample processed for $5 \mathrm{~h}$ at $1230 \mathrm{~K}$ under $10^{8} \mathrm{~Pa}$.

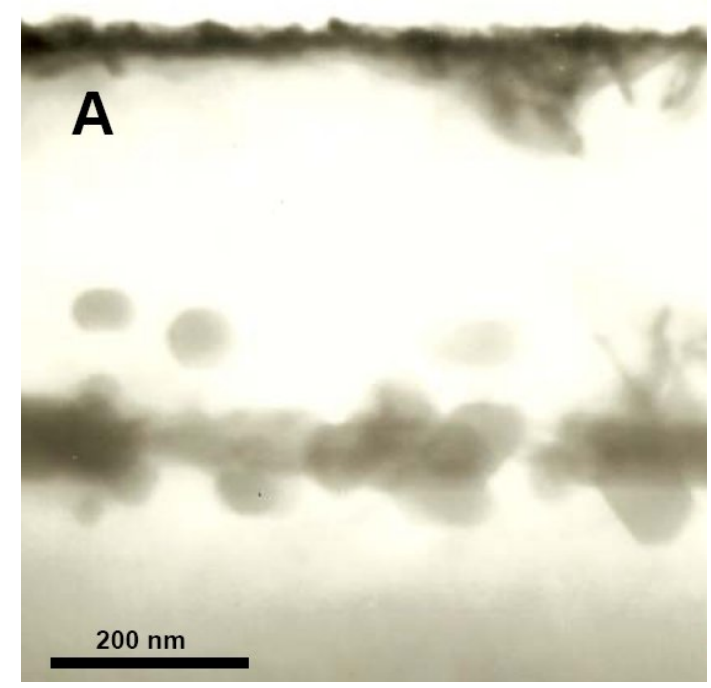

$\mathrm{a}$

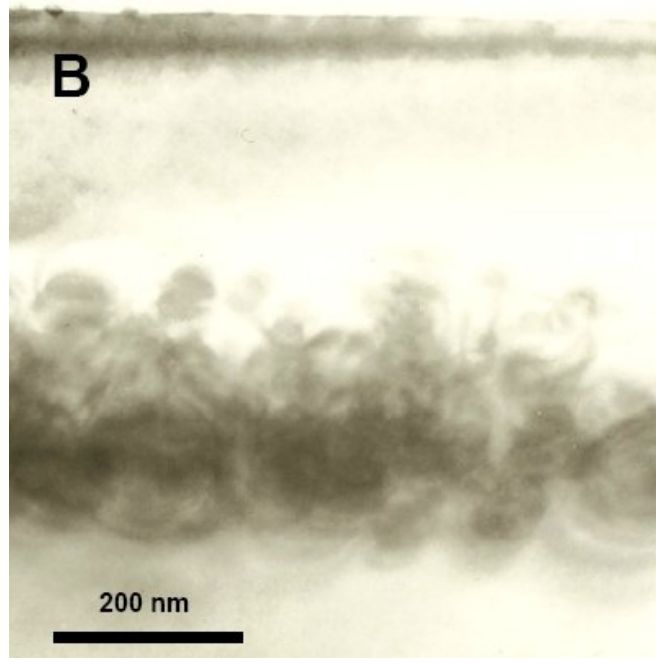

$\mathrm{b}$

Fig. 5. TEM images of the $\mathrm{B} \mathrm{Si}$ :O samples $\left(D=10^{17} \mathrm{~cm}^{-2}\right)$ processed for $5 \mathrm{~h}$ at $1570 \mathrm{~K}$ under $10^{7} \mathrm{~Pa}$ (a) and $1.2 \mathrm{GPa}(\mathrm{b})$ (compare to [5]).

The peak concentration of hydrogen $c_{\mathrm{H}}$ accumulated near $R_{p}$ is dependent crucially on the HT$\mathrm{HP}$ processing conditions. In the case of $\mathrm{B} \mathrm{Si}: \mathrm{O}$ sample processed at $1230 \mathrm{~K}$ under $10^{8} \mathrm{~Pa}$, this concentration exceeds $1 \cdot 10^{20} \mathrm{~cm}^{-3}$ (Fig. 4). 
The quasi-continuous $\mathrm{SiO}_{2-\mathrm{x}}$ layers were formed near $R_{p}$ (Fig. 5) in the case of B Si:O samples processed at $1570 \mathrm{~K}$ (temperature close to that used at SIMOX processing); the sample microstructure is strongly dependent on HP (compare Figs 5a and b). These samples indicate specific accumulation of hydrogen (Figs 6, 7).

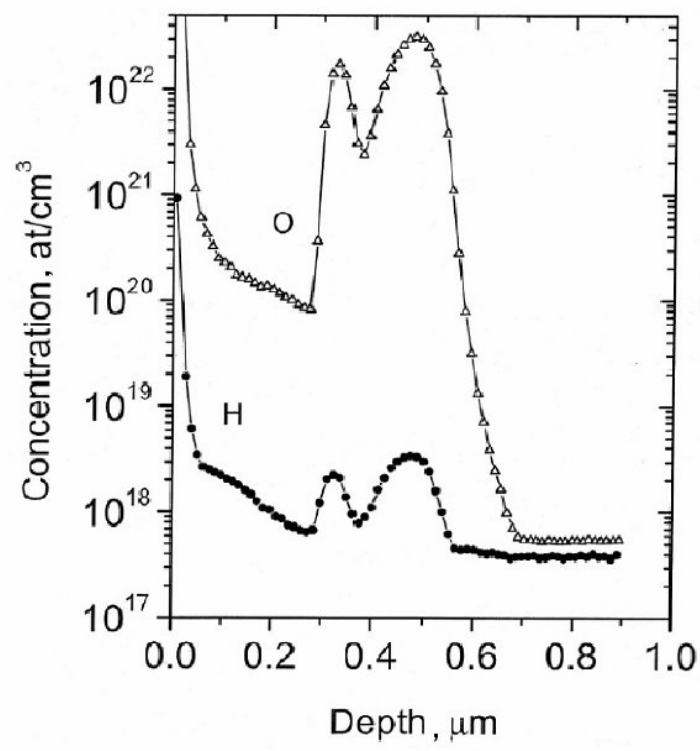

Fig. 6. SIMS depth profiles of oxygen and hydrogen in $\mathrm{Si}: \mathrm{O}, \mathrm{H}$ structure obtained for the B Si:O sample $\left(D=10^{17} \mathrm{~cm}^{-2}\right)$ processed for $5 \mathrm{~h}$ at $1570 \mathrm{~K}$ under $10^{7} \mathrm{~Pa}$ (compare to Fig. 5a).

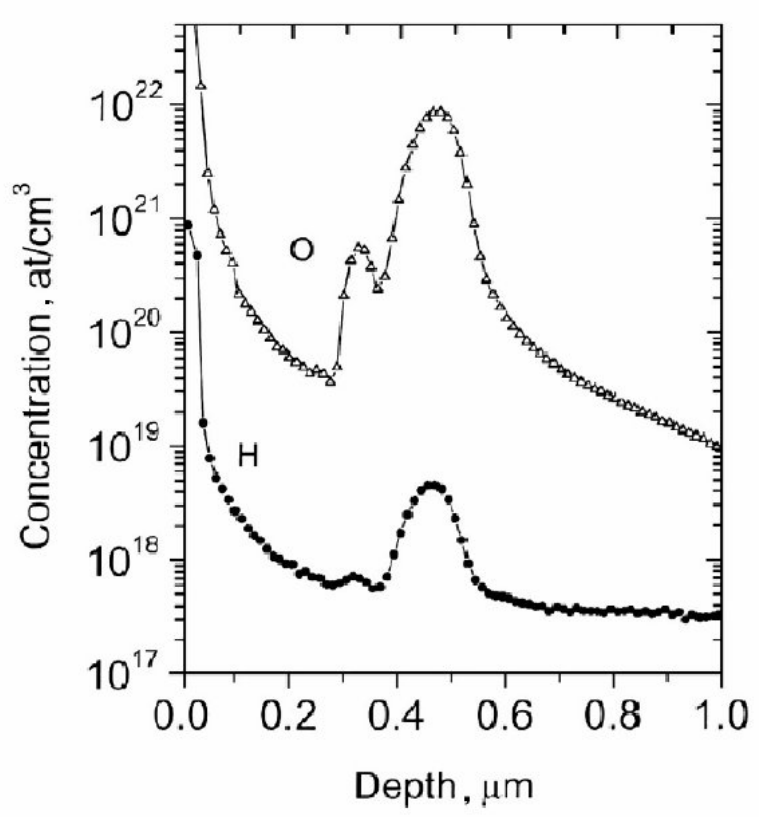

Fig. 7. SIMS depth profiles of oxygen and hydrogen in $\mathrm{Si}: \mathrm{O}, \mathrm{H}$ structure obtained for the B Si:O sample $\left(D=10^{17} \mathrm{~cm}^{-2}\right)$ processed for $5 \mathrm{~h}$ at $1570 \mathrm{~K}$ under $0.6 \mathrm{GPa}$.
It is clearly seen that hydrogen content within the deeper areas of the B Si:O samples processed at 923$1570 \mathrm{~K}$ corresponds to the profile of implanted oxygen and depends on HP applied upon processing. The profiles of oxygen and those of gettered hydrogen depend on the microstructure and therefore on the presence of numerous, HT, HP-induced effects, among them [6]:

- mobility and solubility of implanted oxygen as well as of silicon interstitials and other implantationinduced defects (such as vacancies, $V$ ),

- stability of oxygen agglomerates,

- diffusivity of oxygen as well as of silicon interstitials, $\mathrm{Si}_{i}$, and of vacancies,

- the misfit at the $\mathrm{SiO}_{2} / \mathrm{Si}$ boundary.

Oxygen clustering and precipitation in $\mathrm{Cz}-\mathrm{Si}$ produce shear stress at the $\mathrm{SiO}_{2-\mathrm{x}} / \mathrm{Si}$ boundary. This stress is attributed to the enlarged volume of $\mathrm{SiO}_{2-x}$ precipitates (in comparison to that of the host Si lattice). Other reason of the internal stress is the difference in thermal expansion of $\mathrm{SiO}_{2-x}$ and $\mathrm{Si}$. The misfit and so the shear stress at the $\mathrm{SiO}_{2-x}$ precipitate/Si matrix boundary are affected by HT and HP in accordance [6] with Eq. (1):

$$
\begin{aligned}
& \varepsilon=\varepsilon_{0}+\frac{3 K_{\mathrm{SiO}_{2-\mathrm{x}}}}{K_{\mathrm{SiO}_{2-\mathrm{x}}}+4 G_{\mathrm{Si}}} \times \\
& \times\left[\Delta \mathrm{HT}\left(\beta_{\mathrm{SiO}_{2-\mathrm{x}}}-\beta_{\mathrm{Si}}\right)+\mathrm{HP}\left(\frac{1}{K_{\mathrm{Si}}}-\frac{1}{K_{\mathrm{SiO}_{2-\mathrm{x}}}}\right)\right],
\end{aligned}
$$

where $\varepsilon_{0}$ is the misfit at the $\mathrm{SiO}_{2-\mathrm{x}}$ precipitate/Si matrix boundary at $295 \mathrm{~K}$ under $10^{5} \mathrm{~Pa} ; \beta_{\mathrm{Si}}$ and $\beta_{\mathrm{SiO}_{2-\mathrm{x}}}-$ coefficients of volume thermal expansion; $K_{\mathrm{Si}}$ and $K_{\mathrm{SiO}_{2-\mathrm{x}}}$ - bulk moduli; $G_{\mathrm{Si}}-$ shear modulus (the bottom indexes denote the respective material), and $\Delta \mathrm{HT}=$ $\mathrm{HT}_{\text {experiment }}-295 \mathrm{~K}$.

It means that the shear stress at the $\mathrm{SiO}_{2-x} / \mathrm{Si}$ boundary changes (typically decreases) with HT and HP. For example, in the case of $\mathrm{HP}=1.3 \mathrm{GPa}$ applied at room temperature, the HP induced change of misfit at the $\mathrm{SiO}_{2} / \mathrm{Si}$ boundary, $\Delta \varepsilon\left(\Delta \varepsilon=\varepsilon-\varepsilon_{0}\right)$ can be estimated as equal to about $-2.4 \cdot 10^{-3}[6]$. The values of $K, G$ and $\beta$ are dependent on temperature and pressure; however, these dependences are not known, especially for high temperatures and pressures.

Accumulated hydrogen in the $\mathrm{Si}: \mathrm{O}, \mathrm{H}$ samples remains to be detectable even after subsequent annealing of the $\mathrm{Si}: \mathrm{O}, \mathrm{H}$ structures at temperatures up to $873 \mathrm{~K}$ (Figs 8,9). This suggests chemical interaction of hydrogen with oxygen (probably in the form of substoichiometric $\mathrm{SiO}_{2-\mathrm{x}}$ ), while some part of hydrogen may be bonded to defects (to Si dangling bonds, etc.)

(C) 2010, V. Lashkaryov Institute of Semiconductor Physics, National Academy of Sciences of Ukraine 
[4]. It is necessary to note that similar effects (accumulation of hydrogen at $R_{p}$ and stability of the $\mathrm{SiO}, \mathrm{H}$ structures at high temperatures) were reported earlier for the helium-implanted Si:He samples annealed in hydrogen-containing ambient [7-9].

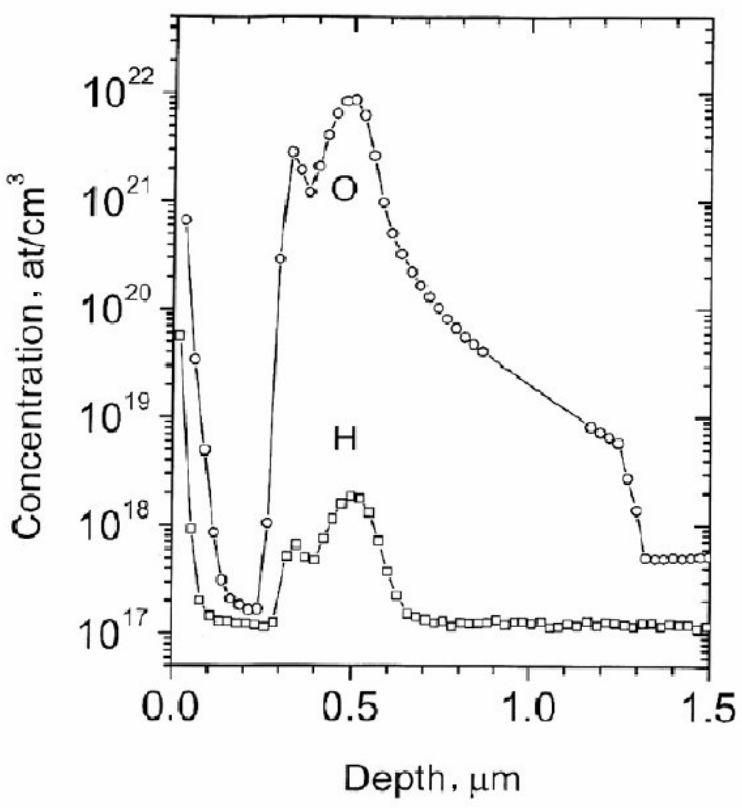

Fig. 8. SIMS depth profiles of oxygen and hydrogen in $\mathrm{Si}: \mathrm{O}, \mathrm{H}$ structure obtained for the B Si:O sample $\left(D=10^{17} \mathrm{~cm}^{-2}\right)$ after processing for $5 \mathrm{~h}$ at $1570 \mathrm{~K}$ under $1.2 \mathrm{GPa}$ (compare to Fig. 5b) and subjected for $1 \mathrm{~h}$ to desorption annealing at $723 \mathrm{~K}$ under $10^{5} \mathrm{~Pa}$.

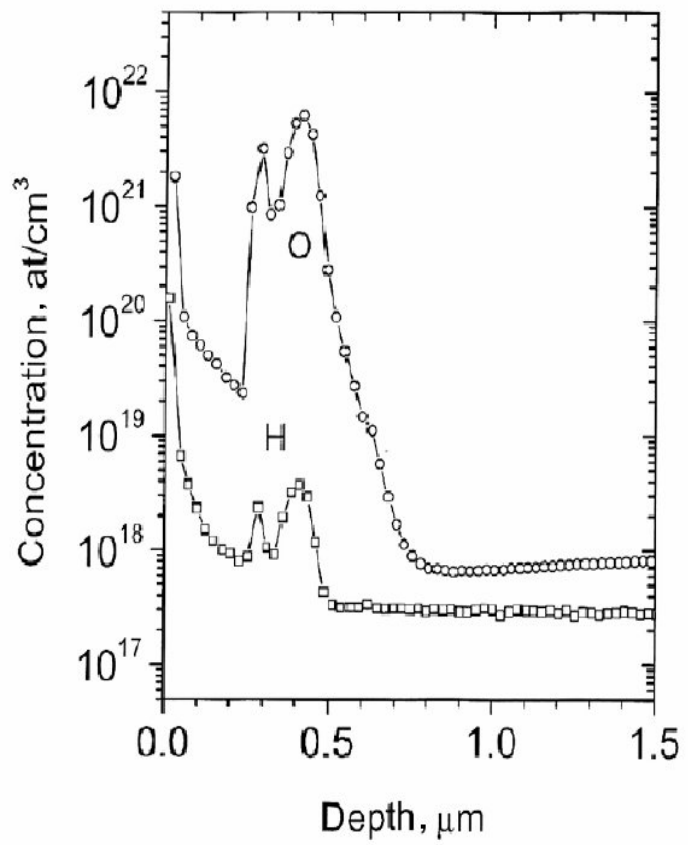

Fig. 9. SIMS depth profiles of oxygen and hydrogen in $\mathrm{Si}: \mathrm{O}, \mathrm{H}$ structure obtained for the B Si:O sample $\left(D=10^{17} \mathrm{~cm}^{-2}\right)$ processed for $5 \mathrm{~h}$ at $1570 \mathrm{~K}$ under $10^{7} \mathrm{~Pa}$ (compare to Figs 5a and 6) and subjected for $1 \mathrm{~h}$ to desorption annealing at $873 \mathrm{~K}$ under $1.1 \mathrm{GPa}$.

\section{Conclusions}

The specific character of hydrogen interaction with defects and oxygen in silicon has been stated for the processed SOI-like structures prepared by oxygen implantation into silicon. This suggests a possibility to use hydrogen plasma treatments for the detection of structural as well as oxygen-related defects in SOI and similar structures prepared by oxygen implantation into monocrystalline silicon.

\section{References}

1. A. Misiuk, A. Barcz, J. Ratajczak, L. Bryja, Effect of high hydrostatic pressure during annealing on silicon implanted with oxygen // J. Mater. Sci.: Mater. in Electronics // 14, p. 295-298 (2003).

2. I.V. Antonova, A. Misiuk, C.A. Londos, Electrical properties of multiple-layer structures formed by implantation of nitrogen or oxygen and annealed under high pressure // J. Appl. Phys. 99, p. 033506 1-6 (2006).

3. A.G. Ulyashin, J.S. Christinsen, B.G. Svensson, R. Kogler, W. Skorupa // Nucl. Instrum. Meth. Phys. Res. B 253 (2006).

4. A. Misiuk, A. Ulyashin, A. Barcz, P. Formanek, Accumulation of hydrogen within implantationdamaged areas in processed $\mathrm{Si}: \mathrm{N}$ and $\mathrm{Si}: \mathrm{O} / /$ Solid State Phenom. 156-158, p. 319-324 (2010).

5. A. Misiuk, J. Ratajczak, J. Katcki, I.V. Antonova, in: Science and Technology of Semiconductor-onInsulator Structures and Devices Operating in a Harsh Environment, Eds D. Flandre et al. Kluver Academic Publishers, 2005, p. 91-96.

6. A. Misiuk, Effect of high hydrostatic pressure during annealing on oxygen containing (oxygen implanted) silicon, in: New Developments in Materials Science Research, Ed. B.M. Caruta. Nova Science Publishers, Inc., New York, p. 181226 (2007).

7. R. Job, A.G. Ulyashin, W.R. Fahrner, A.I. Ivanov, L. Palmetshofer, Oxygen and hydrogen accumulation at buried implantation-damaged layers in hydrogen and helium-implanted Czochralski silicon // Appl. Phys. A 72, p. 325-332 (2001).

8. A.G. Ulyashin, A.I. Ivanov, R. Job, W.R. Fahrner, F.F. Komarov, A.V. Frantskevich, The hydrogen gettering at post-implantation hydrogen plasma treatments of helium and hydrogen implanted Czochralski silicon // Mater. Sci. Eng. B 73, p. 6468 (2000).

9. R. Job, W.R. Fahrner, A.I. Ivanov, L. Palmetshofer, A.G. Ulyashin, The comparison of oxygen and hydrogen gettering at high-temperature postimplantation annealing of hydrogen and helium implanted Czochralski silicon, in: Defect and Impurity Engineering Semiconductors and Devices II, Eds S. Ashok, J. Chevallier, K. Sumino, B.L. Sopori, N. Goetz // MRS Symposium Proc. Series, 510, p. 425-431 (1998).

(C) 2010, V. Lashkaryov Institute of Semiconductor Physics, National Academy of Sciences of Ukraine 